\title{
LA MUJER ROMANA COMO MODELO FAMILIAR EN EL SIGLO XXI
}

Elisa Muñoz Catalán

Universidad de Huelva

https://doi.org/10.33676/EMUI_nomads.57.06

Resumen.- Con la realización del presente trabajo pretendemos investigar sobre cuál ha venido siendo el papel de la mujer desde los esponsales hasta el matrimonio, a lo largo de la Historia. Reparando, muy especialmente, en la madre de familia romana como modelo a seguir para la mujer del siglo XXI, dada su progresiva adquisición de derechos tanto en la vida privada como en la pública.

Así, el título de materfamilias fue evolucionando positivamente y la injuria contra las matronas pasó a ser un delito según el Edicto de adtemptata pudicitia; no sólo por constituir desde una perspectiva de género un atentado contra su honor, como en nuestros días, sino porque dicha conducta punible iba contra las buenas costumbres.

Palabras clave.- matrimonio, esponsales, derechos, buenas costumbres, matrona.

\section{The Roman Woman as a Family Model in the 21 st Century}

Abstract.- With the accomplishment of the writing that follow we pretend to investigate what was the role of women from betrothal to marriage, throughout the History. Repairing, especially, in the roman family mother as a model for the modern woman of the twenty-first century, motivated by their gradual acquisition of rights both in private life and in the public sphere.

As well, materfamilias title evolved positively and slander against the matrons became an offense under the Edict of adtemptata pudicitia; not only because from a gender perspective was an attack on her honor, as today, but because this punishable conduct was against morality.

Keywords.- marriage, betrothal, rigths, morality, matron.

\section{INTRODUCCIÓN}

De entre las instituciones familiares vigentes a lo largo de la Historia, el matrimonio es el más debatido entre la doctrina debido al carácter social del mismo, a su proceso evolutivo frente a otras relaciones de pareja como las tan frecuentes uniones de hecho o convivencia more uxorio, y a la escasez de textos jurídicos o literarios que regulan de manera precisa y unitaria el origen de esta cuestión (López-Rosa, R. y Del Pino Toscano, F., 2001 y 2004; Ortega, A., 2006; Resina, P., 2001: 23-47 
y Robleda, O., 1970). Sin olvidarnos de mencionar el alcance jurídicosocial de la fase previa al mismo, es decir, las promesas verbales de futuro matrimonio o esponsales, los cuales hoy a través la "pedida de mano" se siguen rememorando aunque con un carácter más simbólico pues, como el propio Código Civil español reconoce en su artículo 42, la promesa de matrimonio no produce obligación ni de contraerlo ni de cumplir lo que se hubiere estipulado, si finalmente no se celebra.

Si bien nuestro objeto de estudio se centra en el Derecho Romano de Familia por ser éste el primer Ordenamiento jurídico con influencia en el Mundo occidental actual, a pesar de ser un Derecho histórico y no vigente, lo cierto es que debemos recordar que ya durante la Prehistoria había prevalecido la familia matricéntrica, es decir, aquella formada por madre e hijos donde la mujer tenía la misión principal de consolidar la familia formando una unidad patrimonial autosuficiente; dedicándose a tal efecto a tareas propias de la época, tales como el cultiyo, la caza o la pesca, lo que de igual forma se iba a trasladar a otros terrenos como el político y el religioso. Sin embargo, posteriormente y a consecuencia de las constantes luchas entre los pueblos, el poder de la mujer se fue debilitando, y ésta pasó a desempeñar un papel secundario y dependiente del marido dentro de la unión conyugal, originándose el tránsito hacia la conocida como familia patriarcal o androcéntrica, con un claro predominio del poder del hombre frente al sexo femenino.

Concretamente y, como ya tuvimos ocasión de exponer en trabajos de investigación previos al mencionar la crisis de la familia tradicional burguesa y las distintas uniones extramatrimoniales existentes en Roma (Muñoz, E., 2008:135-137; Muñoz, E., 2014), lo anterior ha originado que en nuestros días estemos haciendo frente a la denominada "violencia de género", pues diariamente no son pocos los medios de comunicación que nos alertan de las desigualdades de género así como del crecimiento de supuestos de violencia ejercida principalmente contra las mujeres y en el ámbito doméstico; lugar este último que, además, se encuentra especialmente protegido por el Sistema jurídico español. Por ello defendemos que si bien la familia, tradicionalmente, se ha venido conformando como ung pieza clave para la luchar contra este tipo de violencia machista cada vez más extendida por el fenómeno de los malos tratos, en la misma línea, dicha institución debe seguir siendo el núcleo básico desde el que se persigan los mencionados delitos en aras a lograr la pretendida igualdad y no discriminación por razón de género.

En este sentido, el objetivo principal que nos planteamos en esta investigación es determinar cuál ha sido la evolución jurídica y consideración social del estatus de la materfamilias como matrona y madre de familia dentro del matrimonio romano para, de alguna forma, comprender el papel que está llamado a realizar la mujer del siglo XXI tras las reformas en materia de derecho antidiscriminatorio de género 
introducidas desde la aprobación de la Ley Orgánica 3/2007, de 22 de Marzo para la Igualdad Efectiva de Mujeres y Hombres (revisión vigente desde 08 de marzo de 2019). De la misma forma que vamos a dar a conocer, en las siguientes líneas, los fundamentos jurídicos que sirvieron de base al Derecho Romano para concebir la injuria contra las mujeres romanas honorables como una conducta punible a través del Edicto de adtemptata pudicitia (Delapuerta, D., 2004: 355-356) '.

\section{LA MUJER ROMANA COMO MODELO ACTUAL}

Antes de proceder al análisis del tema objeto de estudio, entendemos que debemos partir de las siguientes premisas generales. En primer lugar, decir que hasta la etapa clásica (130 a.C.-230 d.C.), la mujer romana carecía de potestad no sólo dentro de la familia sino también en la vida pública. Sin embargo, en términos generales ella disfrutaba de más derechos y prerrogativas que la griega, al menos, en aspectos como los siguientes: a) aunque su actuación en la vida pública seguía estando vetada, en su vida cotidiana disfrutaba de mayor libertad de movimientos; b) no se hallaba recluida en el gineceo, esto es, en la parte de la casa reservada para las damas griegas, sino que podía salir a la calle; c) participaba en los banquetes junto a su esposo y podía asistir a fiestas, juegos y reuniones políticas; d) iba a comprar al mercado y realizaba visitas; el desde el siglo $\vee$ a.C., existía un culto exclusivamente destinado a las mujeres embarazadas, madres 0 matronas, denominado la "matronalia" pero la religión hizo desaparecer esta fiesta pagana.

Si bien cabe resaltar que para lo anterior, debían ir siempre acompañadas pues que una señora saliera sola a la calle estaba considerado como un atentado contra el decoro o las buenas costumbres. También debían llevar la cabeza cubierta por un velo o un manto porque, tal y como sostenía Horacio (56-8 a.C.) $)^{2}$ a la mujer

\footnotetext{
I Sobre la evolución del delito de injurias en el Derecho Romano, la profesora sostiene expresamente que: "Si revisamos la evolución que experimenta el delifo de iniuriae en el Derecho Romano, puede observarse cómo su regulación revela un proceso de progresiva desmaterialización del ilícito, desde la pura lesión física hasta la ofensa a la buena reputación y al decoro [... ] en la identificación de la injuria con afrenta, con contumelia, con ofensa moral producida [...]. No obstante, la identificación de injuria con contumelia no sólo permitió la uniformidad en el tratamiento procesal de los distintos tipos injuriosos, sino que posibilitó también el nacimiento del concepto de injuria indirecta, esto es, de la posibilidad de que determinados sujetos, por el hecho de ostentar la condición de padre, marido o dominus pudieran perseguir, suo nomine, las injurias sufridas por las personas unidas a ellos por relaciones afectivas o de potestad".

2 Quinto Horacio Flaco (56 a.C.-8 a.C.) fue un poeta latino, cuya obra estaba dividida en cuatro grupos: las Odas, los Epodos, las Sátiras y las Epístolas. Solía realizar elogios a los placeres del mundo, a la sencillez, dedicaba ataques contra personas concretas y algunas reflexiones de carácter moral, utilizando un estilo sencillo y equilibrado.
} 
honorable sólo se le veía el rostro y no llevarlo podía ser causa incluso de divorcio. De hecho a las féminas romanas se les distinguía por la forma de vestir, como vamos a tener ocasión de detallar. En cuanto a la opinión generalizada que tenían los romanos sobre las mujeres, en segundo término, nos sirve de ejemplo la idea de Diocleciano (285-305 d.C.) para quien dos mujeres equivalían a un hombre. Asimismo, la matrona no tenía nombre propio y se le llamaba por el nombre del padre pero en femenino, de modo que cuando en la familia había varias hijas, o bien se añadía un ordinal al nombre, o bien se las apodaba "la mayor" o "la menor", en caso de ser sólo dos hermanas. A lo anterior se añade el hecho de que un ciudadano romano no tenía obligación de criar más de una hija, la primogénita, aun cuando la crianza no era necesariamente muy costosa ya que los romanos, al igual que los griegos, pensaban que las damas necesitaban comer menos que los hombres y tampoco su educación obligaba a mayores gastos. En cualquier caso, el ciudadano debía reservar una parte importante de su fortuna para dotar el matrimonio de la hija primogénita si quería emparentarla con otra familia.

Por lo expuesto, el fenómeno de la situación de inferioridad de la hembra se ha caracterizado por ser universal, es decir, se ha venido dando en todos los países, en todas las culturas y entre todas las clases sociales; de ahí que creamos necesario hacer referencia al papel que ha desempeñado la madre de familia a lo largo de la Historia, pero abordado desde una perspectiva de género. En este contexto, vamos a ver que en el Imperio el título de materfamilias no dependía directamente de la procreación sino se encontraba estrechamente relacionado con el matrimonio y significaba la esposa que entraba bajo la potestad del paterfamilias. Investigar sobre la respuesta que daba el Derecho Romano a estos sucesos, creemos que puede resultar interesante y, a la vez, necesario para aplicarlo a nuestra realidad. Términos latinos como "manus", "fragilitas sexus" 0 , incluso, "sexus imbecillis" que encontramos en las fuentes, denotan un concepto que podríamos considerar como "peyorativo" respecto a la posición que la mujer ocupaba en Roma desde la época más primitiva. Aunque, tal y como veremos, la realidad fue cambiando a lo largo del Imperio y cada vez se le reconocieron más derechos a la uxor, como por ejemplo, la posibilidad de ejercitar el divorcio o el reconocimiento de sus derechos sucesorios dentro de la familia, ya en la etapa clásica. En cualquier caso, lo cierto es que el estudio de la mujer tanto en Grecia como en Roma es sumamente complejo pues las noticias que tenemos, casi siempre, proceden de textos escritos por hombres que muestran la ideología patriarcal y androcéntrica propia de la época, y reflejan la discriminación del sexo femenino frente al masculino, así como la situación de indefensión de la esposa respecto al hombre dentro del grupo familiar. 


\section{EVOLUCIÓN JURÍDICA DEL CONCEPTO DE "MADRE DE FAMILIA" III.1. PRECISIONES TERMINOLÓGICAS}

Si bien partimos de la consideración del matrimonio romano como una institución fundamental para el Derecho Romano, a continuación resulta necesario investigar sobre el concepto jurídico de "materfamilias" pues este análisis nos va a servir a la hora de conocer la naturaleza fáctica de la institución matrimonial. Con el término latino materfamilias se alude, de un modo genérico, a la mujer romana matres o matronae que incorporada a una familia ejercía sus funciones como madre y esposa, encargándose de la educación y cuidado tanto de su prole como del propio marido. Por lo que mantenemos que la uxor era el eje central de la institución familiar pues, como madre de familia, tenía encomienda la difícil tarea de perpetuar la especie, alimentarla y educarla dentro del matrimonio.

En época arcaica, ser madre simbolizaba ser esposa bajo potestad de un marido aunque con la evolución del Derecho, el término llegó a significar la esposa de un ciudadano plenamente capaz. De esta forma, se observa cómo la uxor al casarse adquiría la consideración social y jurídica de materfamilias o matrona romana, esto es, que por su condición de esposa de un ciudadano romano tenía la posibilidad de darle hijos con derechos de ciudadanía, y es por esta razón por la que se sostiene que ser materfamilias no dependía del hecho del parto sino del matrimonio mismo. En cualquier caso, la maternidad se veía como un deber de las mujeres hacia la comunidad y de las fuentes se extrae que estas tenían miedo al embarazo y al parto ya que la corta esperanza de vida, en torno a los 30 años, se debía en buena medida a los riesgos de la maternidad pues los embarazos en muchachas jóvenes disparaban el índice de mortalidad.

En este punto, el profesor García Garrido (2008) repara en el análisis del rol que ocupaba la mater en la etapa arcaica y en el cambio de vida que el matrimonio le suponía, comparándolo con el papel del marido. De entre los resultados de sus investigaciones se extrae literalmente que:

"En la antigua familia patriarcal, aunque la mujer estaba sometida a la manus del marido, gozaba de la más alta consideración social como la digna compañera de su esposo [...]. La esposa formaba con el marido una comunidad de bienes y de cultos, en una plena unión de voluntades".

En este contexto, conviene aportar cuáles son las fuentes literarias que tratan sobre la materfamilias y nos han ayudado a definir jurídicamente esta figura, tal y como venimos haciendo en las líneas anteriores:

"Materfamiliae non ante dicebatur, quam vir eius paterfamiliae dictus esset; nec possunt hoc nomine plures in una familia praeter unam 
appellari. Sed nec vidua hoc nomine, nec quae sine filiis est, appellari potest (FESTO, De verborum significatu)".

"Viros nostros, quibus tu voluisti esse nos matres familias (PLAUTO, Stichus, $1,2,41)^{\prime \prime}$.

"(Matrona) Egone hic me patiar frustra in matrimonio, / ubi vir compilet clanculum quidquid domist/ atque ea ad amicam deferat? (PLAUTO, Menaechmi, 4,1)".

Avanzado el Imperio y, concretamente en época republicana, existió una pluralidad de significados del concepto materfamilias debido a la integración progresiva de la mujer en la sociedad romana y en la vida pública e instituciones romanas. A parte del término originario, que la calificaba como aquella esposa bajo el poder del marido en el sentido más técnico y jurídico, se reconoció posteriormente en las fuentes la existencia de un significado más social y menos técnico que concebía a la mater como aquella señora de buenas costumbres. Sobre la evolución de la palabra mater desde el Principado hasta el emperador Justiniano, subrayar que la vieja noción de materfamilias como uxor in mariti manu probablemente había ya desparecido hacia la segunda mitad del siglo I o primera mitad del siglo II d.C., naciendo un nuevo concepto de matrona entendido como sinónimo de materfamilias honorable (Panero, P., 2001: 82 ss.)3; todo ello, consecuencia de esa mayor capacidad jurídica y de obrar adquirida por la mujer.

\section{III.2. LA VESTIMENTA MATRONAL}

Dejando al margen la evolución de este término, en segundo lugar, vamos a reparar en la indumentaria matronal que distinguía a la mater de las demás damas romanas y le posicionaba en ese status. Concretamente, de los textos se desprende que además de la túnica y los cinturones, las prendas principales fueron la stola y la palla. Así lo indica el jurista Ulpiano cuando dispone que:

"Quae matrisfamiliae causa sunt comparata [...] stolae, pallia, tunicae, capitia, zonae, mitrae, quae magis capitis tegendi, quam ornandi causa sunt comparata, plagulae, penulae (D. 34,2,23,2 [Ulp. 44 ad sabinum])".

La profesora Delapuerta (1999) repara en el análisis del texto ulpinianeo y ofrece una definición de cada una de las prendas exclusivas de la materfamilias, resaltando cómo al salir a la calle las matronas distinguidas debían ir totalmente cubiertas para evitar atraer las miradas de los hombres, quienes podían ser incluso objeto de graves sanciones si se sobrepasaban.

\footnotetext{
3 La profesora Panero no duda en afirmar que gracias a la legislación matrimonial de Augusto $y$, en especial, a la Lex lulia de adulteriis (18 a.C.), la materfamilias se consideraba como la mujer honesta.
} 
Sobre la túnica, señalar que era el vestido interior de hombres y mujeres aunque, para ellas, la túnica era más ancha y larga llegando a cubrir tanto los pies como las manos. Por lo que se refiere a la stola, decir que se trataba de un vestido muy amplio, propio y exclusivo de la mater, que le llegaba al suelo formando pliegues y ciñéndose en la cintura con un cíngulo o ceñidor; además, llevaba una pieza ornamental consistente en un volante de púrpura denominado instita. Desde finales de la República y hasta Diocleciano, el antiguo manto cuadrado que cubría la espalda y cabeza denominado ricinium en las XII Tablas (10,3), fue sustituido por una prenda más ancha y larga designada con el nombre de palla.

\section{III.3. LA LIMITACIÓN DE DERECHOS DE LA MATERFAMILIAS ANTES DE LA ETAPA CLÁSICA}

Del concepto anterior, se deriva la siguiente reflexión jurídica sobre aquellos ámbitos en los que nosotros mantenemos que mejor se manifestaba esa incapacidad frente a las instituciones romanas que sufría la mujer romana durante los primeros siglos del Imperio (Guerrero, M., 2004: 297 ss.).

En el orden político, las esposas estaban excluidas de la vida pública pues no podían votar en los comicios, ni ser magistradas o senadoras; tampoco ser procuradoras, ni fiadoras de otro, ni garantizar las deudas ajenas; se les excluía de la adopción, práctica habitual entre los romanos para configurar su familia. Aunque legalmente las féminas romanas estaban apartadas de las instituciones romanas y de la vida pública, la realidad es que sí participaron indirectamente y la manera más común de intervenir era a través de la influencia que ejercían en sus esposos o en sus hijos. En el ámbito sucesorio, se suele mantener qúe es donde la incapacidad de la esposa se manifestaba más claramente. Para el Derecho Romano, la mujer no tenía quien le sucediese de una forma directa a su muerte y no pudieron hacer testamento libremente hasta el siglo II d.C.

En cuanto a la adopción, existía una prohibición de adoptar por parte de las esposas ya que ni siquiera tenían bajo su potestad a los hijos naturales. En contraposición, resaltar que los hombres podían adoptar tanto estando casados como no. Por lo que se refiere a la tutela de las mujeres, éstas fueron consideradas eternas menores de edad hasta Diocleciano (285-305 d.C.) pues se presuponía que necesitaban un tutor para realizar transacciones importantes, tales como aceptar una herencia, hacer testamento, vender tierras, manumitir a un esclavo, etc. Aclarar, en este punto, que en realidad la tutoría era teórica pues, en la práctica, las matronas administraban sus bienes y los de sus hijos. La religión era el ámbito público en el que más participación tuvieron. Excluidas de algunos cultos esenciales en la vida de los romanos, en 
especial de los dioses domésticos o ritos en los que había sacrificios de animales, la participación de las hembras fue imprescindible en su función de profeta y del culto a Vesta. Las vestales eran las mujeres más respetadas de Roma y tenían derechos que no poseían todos los ciudadanos, como por ejemplo, llevar carros o la reserva de un sitio en el podio imperial en los espectáculos.

Finalmente, recordar otras incapacidades de las mujeres dentro de la esfera pública, tales como la representación, la intercesión, la postulación en nombre ajeno, o la acusación pública. En cualquier caso, todas ellas tenían restringido su ámbito de actuación a su propia persona, a sus propios intereses y, en ese sentido, cualquier actuación que sobrepasase ese estrecho marco, era un oficio civil, viril y, por tanto, prohibido al sexo femenino. La figura femenina carecía, en suma, de capacidad para representar a otro y, este hecho, le hacía incapaz de realizar multitud de oficios que se entendían masculinos.

\section{EL EDICTO DE ADTEMPTATA PUDICITIA Y LA INJURIA CONTRA LAS MUJERES}

Mención especial requiere el estudio de la situación jurídica de la materfamilias según el Edictum de adtemptata pudicitia pues, aun cuando desde la Ley de las XII Tablas se habían hecho diversos intentos para proteger a las damas de acercamientos indeseados, no existía todavía en época republicana regulación alguna sobre lo que se conocía como iniura. Tanto es así que en los supuestos de insinuaciones consentidas por alguna de las partes o comportamientos escandalosos, se trataba dentro de la propia familia a través del consilium propinquorum o consejo doméstico.

En este ámbito y, con la intención de restaurar las bases morales del matrimonio, el emperador Augusto propuso en el 18 a.C la Lex Iulia de adulteriis coercendis que castigaba como adulterio o estrupo toda relación sexual mantenida fuera del matrimonio y declaraba de ilícita toda unión extraconyugal con mujeres de baja condición social. Existían varias formas de comportamiento inaceptable que se englobaban dentro del concepto de "iniuria" haciendo responsable al que lo realizaba de una reparación por daños, y uno de esos delitos era el de adtemptata pudicitia consistente en atentar contra la buena fama de una doncella honesta, quedando a salvo aquel hombre seductor que lo hubiera hecho por broma o por honesta oficiosidad 4 .

El Edictum de adtemptata pudicitia era, pues, un edicto promulgado por el Pretor urbano en materia de iniuria por el que se protegía y castigaba conductas específicas contra las buenas costumbres, consideradas punibles por constituir atentados contra la honorabilidad,

${ }^{4}$ Sobre esta cuestión, vid. por todos, D. 47,10,15,15-16 (Ulp. 77 ad edictum). 
el decoro y el pudor de ciertas personas, como eran la materfamilias, el praetextatus y la praetextata o hijos de familias nobles portadores de la toga praetexta. No conocemos ni el nombre del Pretor urbano que promulgó el edicto, ni la sanción impuesta, ni la fecha exacta de aprobación, ni tampoco su contenido, sin embargo, en cuanto a la fecha de promulgación la profesora Guerrero (2004) 5 advierte que ha sido la doctrina la que ha estimado su publicación aproximadamente entre finales del siglo II y principios del siglo I a.C.

Por lo que se refiere al contenido del citado texto, al no conservarse el edicto, debemos acudir a la reconstrucción realizada por los romanistas a partir de las referencias existentes, siendo una de la más aceptada entre la Communis opinio la de $O$. Lenel, de la que extraemos los elementos regulados edictalmente (Bravo, M. J., 1998: 250-254): "Si quis matrifamilias aut praetextato praetextataeve comitem abduxisse sive quis eum eamve adversus bonos mores appellasse adsectatusve esse dicetur". Detengámonos en analizar los dos elementos que componen este delito:

a) Elemento subjetivo o intencionalidad requeridab: Para que hubiese delito de iniura, el edicto exigía la intención del ofensor de cometer el delito y atentar contra las buenas costumbres. Por lo que en caso de error in personam, confusión, broma $u$ honesta oficiosidad, no habría castigo y se excluía la responsabilidad o se minoraba la culpa al no quedar demostrado el dolo o intención de atentar voluntariamente contra el pudor de las mater, doncellas, o jóvenes portadores de la toga praetexta.

En el Derecho clásico esa intención de cometer alguna de las tres conductas perseguidas podía designarse con una gran variedad de términos sinónimos, como eran, fraus, culpa, animus, voluntas y, muy especialmente, el concepto de dolus. Sobre el pudor, Bravo Bosch (1998) sostiene que la forma de vestir era muy importante a la hora de concretar la conducta punible del agresor pues tanto las mater como los jóvenes llevaban unas túnicas que simbolizaban tanto sus estatus jurídicos como su decoro. Si un hombre intentaba seducir a doncellas vestidas con traje de esclavas se calificaba como una falta menor y, mucho menor, si eran damas vestidas con trajes de meretrices y no de señoras honestas; así, pues, si una dama no llevaba traje de señora y alguien atentaba contra su pudor o le quitaba al acompañante, el que

5 La profesora Guerrero aporta una idea de mater, en base a la reconstrucción cronológica y conceptual del edicto realizada por $O$. Lenel en Das Edictum perpetuum

6 Sobre el elemento subjetivo, las fuentes que mejor resalta la intencionalidad requerida para que se cometiera iniura son: D. 47,10,3,4 (Ulp. 41 ad edictum); D. 47,10,15,23 (Ulp. 77 ad edictum); y, muy especialmente, D. 47,10,15,15 (Ulp. 77 ad edictum). 
atentaba no quedaba sometido a la acción de injurias. Sin embargo, si una mujer libre (virgo) se vestía como esclava, se exponía a estos acosos dada su indumentaria, por lo que el castigo al ofensor sería menor ya que la fémina dio pie a esa falta.

b) Elemento objetivo o conductas punibles y sujetos protegidos: Para que surgiese el delito no bastaba el empleo de palabras soeces y groseras, el seguir a una persona o el alejarle de su acompañante, sino que las actuaciones punibles debían producirse contra los bonos mores; la contravención a las buenas costumbres era común a los tres casos de iniura contemplados en el edicto y conllevaba responsabilidad para las personas que las incumplían. En base a los textos de Ulpiano7, la reconstrucción de O. Lenel y el análisis de la profesora Delapuerta (1999 y 2004)8, a continuación realizamos una breve referencia sobre las personas protegidas:

- La Materfamilias: Se hace referencia a aquella mujer que vivía honestamente y conforme a las buenas costumbres siendo indiferente si estuviera casada o viuda, fuera ingenua o liberta. Por tanto, se trataría de un concepto social y clasista del término materfamilias que resalta la honorabilidad de la esposa como modelo de dignidad y pudor.

- El Praetextatus (que llevaba la toga praetexta) y la praetextata (jóvenes de ambos sexos pertenecientes a familias nobles portadores de este tipo de togas): Estos sujetos estaban protegidos edictalmente por vestir la toga praetexta, esto es, una túnica blanca adornada de púrpura, a diferencia de los demás ciudadanos que las llevaban de un solo color; esta toga era llevada también por los magistrados, los sacerdotes, y los adolescentes pertenecientes a familias nobles, pues los hijos de familias pobres vestían con una toga simple. Delapuerta (1999) al tratar esta cuestión sostiene que:

"El término praetextatus es indicador de un determinado rango social [...]. El tiempo de utilización de esta prenda variaba según el sexo: Las chicas la abandonaban en el momento de contraer matrimonio, y los chicos en el momento en que tomaban la toga virilis o toga pura, es

\footnotetext{
7 Recogidos en D. 47, 10,15,15-23 (Ulp. 77 ad edictum).

8 Sobre los tipos de conductas punibles, la profesora Delapuerta afirma en sus obras que: "Siguiendo la reconstrucción edictal [...] se concreta en tres tipos de conductas punibles: a. cortejar con dulces e insinuantes palabras eróticas (appellare). b. seguir por la calle de forma discreta y fastidiosamente insistente (adsectari). c. alejar al acompañante (comes) que determinadas personas llevaban siempre en sus apariciones en público como escudo protector de su honor (comitem abducere). Se trata de tres actividades que, claramente, sólo pueden desarrollarse en la calle o en lugar de público tránsito y que comparten un cierto carácter equívoco, incierto".

9 Para un concepto de "madre de familia" en Roma, vid. por todos, D. 50,16,46,1 (Ulp. 59 ad edictum): "'Materfamilias" accipere debemos eam, quae non inhonestae vixit; matrem enim familias a ceteris feminis mores discernunt, atque separant; proinde nihil intererit, nupta sit, an vidua, ingenua sit, an libertina; nam neque nuptiae, neque natales faciunt matremfamilias, sed boni mores"; FESTUS, De Verborum Significatu., p. 112: "Appellabant eas fere, quibus stolas habendi ius erat".
} 
decir, hacia los 17 años, en tiempos de la República (LIVIO, 22, 57,9), y al cumplir los 14 años, en tiempos del Imperio (TÁCITO, Ann. 12,41)".

En cuanto a las tres conductas punibles edictalmente, señalar apellare, adsectari, y comitem abducere:

- El término apellare 10 , significaba realizar proposiciones deshonestas y cortejar con insinuantes palabras inmorales, de manera que hubiese un atentado al pudor. Para que fuese perseguido por el edicto las proposiciones no podían haberse hecho de broma ni sin intención lesiva, sino debían realizarse contra las buenas costumbres o normas sociales de la época.

- Con adsectari 11, se aludía a las conductas consistentes en perseguir constantemente los pasos de alguien pero de manera fastidiosa, abusiva, insistente y en silencio, de tal forma, que el status social de la persona acosada quedase dañado por tal reiteración; sin embargo, no existía esta conducta cuando se perseguía por diversión o broma,

- Comitem abducere 12 es la tercera conducta perseguida como delito de adtemptata pudicitia, consistente en tratar de alejar al acompañante, comes (libre o esclavo, varón o hembra). de mujeres o praetextatus pertenecientes a las clases sociales más elevadas, que siempre iban custodiados como símbolo de honradez y defensa de su pudor; debía hacerse contra las buenas costumbres y con la intención real de avergonzarles en público y exponerles a la mala fama como si se tratase de meretrices o personas de condición servil.

Por lo expuesto, para que hubiese delito de iniuria hacía falta la voluntad e intención efectiva de atentar contra el decoro y la buena fama de la materfamilias portadora del habitus matronalis, el praetextatus y los niños de clase alta que llevasen la toga praetexta.

\section{CONCLUSIONES}

A modo de conclusión final de nuestro trabajo nos gustaría poner de manifiesto cómo el Derecho Romano construyó, desde los orígenes de su Imperio, una ordenación jurídica de la división de los sexos muy compleja basada, principalmente, en la carencia de potestad de las mujeres dentro del matrimonio y en lo que se refiere a la herencia, pues no tenían descendiente de forma directa a su muerte. De igual modo, tal y como hemos venido advirtiendo, éstas no podían ejercer cualquier profesión o cargo público como magistradas, senadoras, procuradoras

10 En cuanto a las fuentes que tratan sobre appellare, vid. por todos, D. 47, 10,15,21-23 (UIp. 77 ad edictum); QUINT., Inst. orat., 4, 2,98; DECL. 363; VALERIO MAXIMO, 6, 1,7 y 11. 11 Reparando en las fuentes que regulan la conducta de adsectari, señalar: D. 47,10,15,22-23 (Ulp. 77 ad edictum); Gai. 3, 220; CIC. MUR. 34,70; CIC. MUR. 35,73;

12 Los textos que tratan esta conducta son: D. 47,10,15,15-19 (Ulp. 77 ad edictum); QUINT, Inst. Orat., 1, 1,12; CICERÓN, Acic.,74; SUETONIO, Aug., 44,2. 
- abogadas, a diferencia de los ciudadanos romanos varones quienes tenían plenos derechos. Puede decirse, en este sentido, que se privaba a la mujer de una autonomía que afectaba al ámbito jurídico, político y se le limitaba a la esfera del hogar y de lo doméstico con la finalidad de procreación de los hijos habidos en una unión marital, si bien, ni en este último caso la madre ejercía un poder público sino meramente privado o interno. Sin embargo, un ejemplo de dama romana que se distinguía de las demás y que hemos tenido ocasión de resaltar eran las honorables materfamlias, pues su posición jurídica y social les hacía llevar una vestimenta diferente que simbolizaba el respeto frente a terceros como señora virtuosa.

Tanto es así que incluso si analizamos el término "esposa" (del latín, "sponsus"), creemos que igualmente nos encontramos con un sentido algo despectivo desde sus orígenes, pues aunque dicha palabra proviene de la celebración desde época arcaica de los esponsales o promesas de un futuro matrimonio, lo cierto es que actualmente alude a una atadura o ligazón para no ser libre de anular la celebración de un matrimonio tras dicho compromiso. No obstante lo anterior, ya desde época clásica, se produjo una lucha por la igualdad de ambos sexos y la mujer empezó a adquirir paulatinamente determinados derechos personales, patrimoniales e, incluso, sucesorios dentro de la familia romana; en particular, pudieron acumular cierta riqueza, heredar, ser beneficiarias de un testamento y tenían su propia dote. En relación con el trabajo femenino, además de realizar oficios que consideraban específicamente propios de su sexo, llevaron a cabo también actividades artesanales y comerciales, con la excepción del ejercicio de la banca y del cambio, del que estaban excluidas al ser actividades que suponían operaciones por cuenta ajena. En el ámbito jurídico, igualmente participaron, manifestando sus preocupaciones por rescriptos o constituciones imperiales con fuerza de ley.

En nuestro sistema vigente, la Constitución española de 1978 proclama en el artículo 14 el derecho fundamental a la igualdad y a la no discriminación por razón de sexo, consagrando la obligación de los poderes públicos de promover las condiciones para que la igualdad del individuo y de los grupos en que se integra sean reales y efectivas (artículo 9.2). Y es precisamente la antes mencionada Ley Orgánica 3/2007, de 22 de Marzo para la Igualdad Efectiva de Mujeres y Hombres (revisión vigente desde 08 de marzo de 2019), ta normativa que en los últimos años nos ha aportado grandes novedades en esta materia, como por ejemplo, la prevención de las conductas discriminatorias y la previsión de políticas activas para hacer efectivo el principio de igualdad; prestándose una especial atención a la corrección de la desigualdad en las relaciones laborales al reconocerse el derecho a la conciliación de la vida personal, familiar y laboral, y al fomentarse una mayor corresponsabilidad entre mujeres y hombres en la asunción de obligaciones familiares. 
En suma, de forma paralela a lo que ocurría en Roma, en nuestros días tanto las injurias como las calumnias son delitos en los que el bien jurídico protegido es el honor, y este derecho fundamental tal y como lo configura nuestra Constitución española, corresponde a "todos" y ha de tener un contenido general. Por tanto, podemos concluir manteniendo que si bien en un principio pudiera parecer que la liberación de la mujer fue un logro del siglo XX, bajo las premisas anteriores hemos demostrado cómo las mujeres de la prehistoria y concretamente las mujeres romanas del siglo I d.C., habían alcanzado un nivel de autonomía comparable al logrado al final del siglo XX en Europa. Por lo que la siguiente frase de Catón (año 195 a.C.) ${ }^{13}$ nos sirve para concluir esta investigación ya que, al referirse a las mujeres, el censor afirmó que: "Tan pronto como hayan empezado a ser iguales, serán superiores".

\section{OVI. REFERENCIAS BIBLIOGRÁFICAS}

(1998) BRAVO BOSCH, M. J., "Algunas consideraciones sobre el Edictum de Adtemptata ad pudicitia", en Actas del II Congreso Iberoamericano de Derecho Romano, Editorial Servicio de Publicaciones de la Universidad de Murcia, Murcia, pp. 41-53.

(1999) DELAPUERTA MONTOYA, D., Estudio sobre el Edictum de Adtemptata Pudicitia, Editorial Tirant Lo Blanch, Valencia.

(2004) D. DELAPUERTA MONTOYA, D. (2004), La Contumelia indirecta en los ataques a la buena reputación de la mujer e hijos, en LÓPEZ-ROSA, R.; DEL PINO-TOSCANO, F. (Eds.), El Derecho de Familia. De Roma al Derecho Actual, Editorial Servicio de Publicaciones de la Universidad de Huelva, Huelva, pp. 355-372.

(2008) GARCÍA GARRIDO, M. J., Derecho Privado Romano. Casos. Acciones. Instituciones, Ediciones Académicas, Madrid.

(2004) GUERRERO LEBRÓN, M., La idea de materfamilias en el Edictum de Adtemptata Pudicitia, en LÓPEZ-ROSA, R.; DEL PINO-TOSCANO, F. (Eds.), El Derecho de Familia. De Roma al Derecho Actual, Editorial Servicio de Publicaciones de la Universidad de Huelva, Huelva, pp. 297310.

(2001) LÓPEZ-ROSA, R.; DEL PINO-TOSCANO, F., El Derecho de Familia y los Derechos Reales en la Romanística española, Editorial Servicio de Publicaciones de la Universidad de Huelva, Huelva.

(2004) LÓPEZ-ROSA, R; DEL PINO-TOSCANO, F., El Derecho de Familia. De Roma al Derecho Actual, Editorial Servicio de Publicaciones de la Universidad de Huelva, Huelva.

13 Livio, Ad Urbe Condita, XXXIV, 3. 
(2014) MUÑOZ CATALÁN, E., "Perspectiva evolutiva de las tradicionales parejas de hecho frente a las uniones intersexuales". En: Nómadas. Revista Crítica de Ciencias Sociales y Jurídicas, 43 (3).

(2008) MUÑOZ CATALÁN, E., La consideración de la mujer casada, de Roma a nuestros días, en GILES, R y MORA, M. (Coords.), El Derecho Antidiscriminatorio de Género. Estudio Pluridisciplinar de la Ley Orgánica 3/2007, de 22 de Marzo para la Igualdad Efectiva de Mujeres y Hombres. Editorial: @becedario, Badajoz, pp. 135-137.

(2006) ORTEGA CARRILLO DE ALBORNOZ, A., Terminología, definiciones y ritos de las nupcias romanas. La trascendencia de su simbología en el matrimonio moderno, Editorial Dykinson, Madrid.

(2001) PANERO ORIA, P., IUs occidendi et lus accusandi en la Lex Iulia de adulteriis coercendis, Editorial Tirant Lo Blanch, Valencia.

(2001) RESINA SOLA, P., El estudio del Derecho de Familia a través de la doctrina romanística española (1940-2000), en LÓPEZ-ROSA, R.; DEL PINO-TOSCANO, F. (Eds.), El Derecho de Familia y los Derechos Reales en la Romanística española, Editorial Servicio de Publicaciones de la Universidad de Huelva, Huelva, pp. 23-47.

(1970) ROBLEDA, O., El matrimonio en Derecho Romano. Esencia, requisitos de validez, efectos, disolubilidad, Librería Editrice Università Gregoriana, Roma. 